\section{Las configuraciones familiares desde la prensa argentina (1993-2011). Apuntes sobre los discursos sobre las violencias en las escuelas}

Family configurations in the Argentinian press (1993-2011). Notes on the discourses on violence in schools.

\section{VIRGINIA SAEZ}

\section{Resumen}

El presente trabajo se focaliza en los discursos mediáticos sobre las configuraciones familiares

Doctora en Educación y magíster en Educación, Pedagogías Críticas y Problemáticas Socioeducativas por la Facultad de Filosofía y Letras (FFYL) de la Universidad de Buenos Aires (UBA). Becaria posdoctoral del Consejo Nacional de Investigaciones Científicas y Técnicas (CONICET). Desarrolla sus investigaciones en el marco del Programa de Investigación sobre Transformaciones Sociales, Subjetividad y Procesos Educativos. Directora: Carina V. Kaplan.Sede: Instituto de Investigaciones en Ciencias de la Educación (IICE), Facultad de Filosofía y Letras (FFYL) de la Universidad de Buenos Aires (UBA). Buenos Aires. Argentina. Dirección Postal: Córdoba 646 Lanús Este CP: 1823. Correo electrónico: educaciondelamirada@gmail.com en los episodios de violencia en las escuelas en Argentina en el período 1993-2011. Dadas las características del objeto de indagación, el abordaje metodológico fue cualitativo y la información se analizó en el marco del análisis socioeducativo del discurso. Entre los resultados obtenidos observamos que los grupos familiares son representados desde modelos ideales y percibidos según sus condicionamientos materiales desiguales. Se representa ciertas configuraciones familiares como grupos en riesgo, víctimas y responsables de las situaciones de violencia en el espacio escolar. Las estrategias comunicacionales utilizadas por la prensa coinciden en naturalizar la producción de cuidado a cargo de las familias e invisibilizar la falta de producción del cuidado por parte de las políticas públicas. Por su originalidad, este estudio constituye un antecedente para futuras indagaciones sobre las representaciones mediáticas de los grupos familiares en el espacio escolar.

Palabras clave: Familia, escuela, medios de comunicación, violencia, estigmatización.

\footnotetext{
Abstract

The present work focuses on media discourses on family configurations in the episodes of violence in schools in Argentina in the period 1993-2011. Given the characteristics of the object of inquiry, the methodological approach applied was qualitative and the information was analyzed in the context of the socio-educational discourse analysis. Among the results obtained, we noted that family groups are represented from ideal and perceived models according to their unequal material constraints. Certain family
} 
configurations are represented as groups at risk, victims and perpetrators of the violence in the school space. The communication strategies used by the press coincide in naturalizing the production of care by the family, hiding the lack of production of care on the part of public policies. Due to its originality, this study constitutes a precedent for future inquiries on media representations of families in the school space.

Key words: Family, school, media, violence, stigmatization.

\section{Introducción}

Las prácticas discursivas en los medios de comunicación reiteran la violencia en el espacio escolar como un problema con desenfreno, que afecta a la infancia, a la juventud y a la familia. El periodismo cuenta con una posición privilegiada en la producción de discursos sociales dado que dispone de los medios más potentes para hacerlos circular e imponerlos (Bourdieu 2002). Las noticias periodísticas, en tanto construcciones de la realidad (Verón 1981), producen y reproducen principios de visión y división del mundo social. Los modos por los cuales la prensa construye el vinculo entre violencia y escuela como parte de una agenda mediática generan efectos que reproducen discursos e imágenes sobre la escuela y los sujetos que la habitan (Bourdieu y Wacquant 2005).

Los discursos de los medios de comunicación, sobre las violencias en las escuelas hacen sonar la alarma educativa. Se trata de discursos que circulan por dentro y por fuera de la escuela (Lahire 1999). Junto con Finocchio sostenemos que "Lo que se piensa y se dice públicamente sobre la educación no sólo connota las miradas de quienes la observan y comentan (o lamentan) sobre ella, sino que, convertido en el sentido común pedagógico de directivos, docentes, padres y alumnos, también atraviesa las decisiones cotidianas del mundo escolar" (Finocchio 2009:11).

Los estudios que abordan los discursos mediáticos sobre las violencias en las escuelas encuentran en la representación de las configuraciones familiares una dimensión a explorar para avanzar en la conceptualización de las violencias en las instituciones educativas. El término "violencia" reviste la idea de desviación y las intervenciones van a corregir cuestiones individuales del estudiante 0 familiares. (Villanueva, 2005). Desde el discurso mediático se establece una asociación entre las escuelas de gestión estatal, alumnos conflictivos y familias desestructuradas (Saez 2014 y Piñuel Raigada, Gaitán Moya y García 2007).

Ahora bien, la representación social de la familia moderna es parte de una lucha simbólica asociada al establecimiento de una configuración social determinada. Roswitha Hipp (2006) muestra como en los orígenes históricos de la familia moderna en Europa y Latinoamérica, la Iglesia, el Estado y los pensadores ocuparon un papel relevante en el establecimiento de un modelo de orden social. En este sentido, la prensa ocupó un lugar fundamental donde legitimar determinados modelos de configuraciones familiares. Los medios de comunicación, como productores de discursos, son portadores de un capital simbólico acumulado que es el que sostiene y legitima el ejercicio del poder simbólico (Bourdieu 1988). A través de estrategias 
discursivas, históricamente construidas, se elaboran ciertas representaciones de lo social como verosímiles (Martini 2004).

Ahora bien, la representación de la familia en el discurso mediático fue objeto de varios estudios. Algunos evidencian como desde la prensa gráfica hay una asociación de determinadas configuraciones familiares con la felicidad y un modelo de convivencia. Los medios de comunicación reproducen y construyen imaginarios sobre lo que significaba una vida familiar feliz que homogeneiza $y$ repite un modelo idealizado sin conflictos 0 problemas (Sosenski y López León 2015 y Crespo Sánchez 2014 y 2015). A través de su discurso enfatizan que los niños serían felices en proporción al vínculo con su núcleo familiar. Asimismo, resaltan una poca alusión a sectores obreros o campesinos en contraposición a la repetición de escenas familiares que aluden a las clases medias y altas (Sosenski y López León 2015). Respecto a la circulación de estos discursos, la difusión de un modelo ideal de familia se promociona en etapas marcadas por conflictividad social y política (Crespo Sánchez 2014 y 2015) y en contextos de cambios legislativos referidos al matrimonio y la familia, como es el siglo XXI.

Dados estos antecedentes, resulta relevante analizar los discursos mediáticos sobre las configuraciones familiares del fenómeno de las violencias en las escuelas. En tanto sostenemos como hipótesis inicial que dicha mediatización tiene efectos simbólicos sobre los procesos de estigmatización de ciertas configuraciones familiares. Lo que se piensa y dice públicamente sobre la educación incide en la cotidianeidad de la tarea escolar.

\section{Enfoque teórico y metodológico}

Toda práctica social está conformada por una serie de momentos, algunos de los cuales son discursivos y otros no (Fairclough 2008). En este trabajo, sostendremos que algunas prácticas sociales son eminentemente discursivas y entre ellas ubicamos las prácticas periodísticas. De este modo, entendemos que dichas prácticas atraviesan las coyunturas de modos particulares, construyen de esta manera, algunos de los momentos discursivos de toda práctica. Sin embargo, el fundamento de este trabajo es el análisis del discurso de los medios entendidos como "máquinas de producción de realidad social" (Verón 1987: 7). No pretendemos sostener con esto que las lo que se presenta en las coberturas sean pura ficción mediática. Tampoco vamos a afirmar que las prácticas periodísticas nos acercan diariamente a una copia fiel de la "realidad de los hechos". Se trata, en todo caso, de que producen aquello que consumimos cotidianamente como actualidad. Una prueba de ello es que solamente algunos acontecimientos devienen en noticia. Parecería que sólo una vez que los medios "hacen" noticia de un determinado acontecimiento, éste logra trascender sus propios límites espaciotemporales: sus prácticas y protagonistas se vuelven públicos y esta "publicidad" suscita otras series de prácticas discursivas y no discursivas.

También se asume que, si bien no quedará demostrado en este trabajo, las representaciones sociales que ofrecen los medios no son uniformes ni estables (Raiter y Zullo 2008). Desde este punto de vista en etapas posteriores del análisis, esperamos encontrar diferencias en la presentación de los hechos y de sus protagonistas entre estos y otros matutinos $y$, al 
mismo tiempo, cambios en un mismo medio al pasar de un conflicto a otro.

Desde una perspectiva socioeducativa consideramos que las violencias en las escuelas no son un correlato mecánico de la violencia social, aunque es allí donde se originan y cobran su sentido más hondo. Ciertas mediaciones intervienen en la escuela para que esta posibilite algo distinto que los comportamientos brutales que suscitan las sociedades capitalistas salvajes (Kaplan 2009).

El objetivo de este estudio consistió en analizar e interpretar las representaciones de la prensa platense sobre las configuraciones familiares en los discursos de las violencias en las escuelas en el período 1993-2011. Este trabajo no trata de dar cuenta de los hechos ocurridos sino de la reconstrucción de los mismos que presentaron los periódicos elegidos. Rastrear las formas discursivas de construcción de estos acontecimientos.

Se delimitaron como unidades de análisis los discursos presentes en las coberturas sobre las configuraciones familiares en los episodios de violencia en las escuelas en los diarios El Día, Hoy, Extra y Diagonales de la ciudad de La Plata en el período 1993-2011. El corpus se conforma por 108 notas: 45 del diario El Día, 31 del diario Hoy, 27 del diario Extra y 5 del diario Diagonales.

El año de inicio del relevamiento fue seleccionado dado que en 1993 se sanciona la Ley Federal de Educación 24.195. Esta normativa constituye un hito relevante por ser la primera ley que regula el sistema educativo argentino en su conjunto, y establece diez años de educación obligatoria para los ciudadanos, desde la sala de 5 años hasta noveno año del nivel primario.
Es necesario destacar que se eligen los medios gráficos dado que son una referencia dominante y marcan tendencia informativa para el resto de los medios de comunicación (Bonilla Vélez y Tamayo Gómez 2007). También interesa la materialidad de los diarios y la potencialidad del texto escrito para observar las distintas formas de nominación del fenómeno. Se seleccionaron los medios de la ciudad de La Plata porque es la capital de la provincia de Buenos Aires y es considerada su principal centro político, administrativo y educativo. Estas características la hacen significativa del presente estudio, por ser un espacio social a partir del cual se toman decisiones que afectan a todas las provincias de la República Argentina.

El abordaje metodológico es cualitativo, y el diseño de investigación asume un carácter exploratorio. El muestreo es finalístico: se seleccionaron las prácticas discursivas que aportaran información de interés en relación al objetivo estipulado. El estudio nos permitió analizar el objeto de estudio en el período comprendido entre 1993 y 2011 . No se pretendió analizar cómo han ido modificándose las representaciones mediáticas a lo largo del lapso elegido, sino observar las continuidades en la caracterización de las configuraciones familiares en los discursos sobre las violencias en las escuelas. Esto nos brindó bases connotativas para describir el fenómeno. Hemos abordado todas las secciones de cada periódico. En el conjunto hallamos gran cantidad de semejanzas y pocas diferencias, por tal motivo no se realizó una distinción analítica por cada diario.

Ahora bien, como se demostró en trabajos anteriores (Saez 2015) existen tensiones y debates presentes en los estudios sobre medios de comunicación que abordan temáticas 
sociales. Desde las corrientes de la Lingüística Crítica (Raiter y Zullo 2008) y del Análisis Crítico del Discurso (Van Dijk 2007) evidencian que no hay una forma única de abordar los discursos mediáticos y manifiestan su preocupación por la reproducción de la desigualdad. En afinidad con esta preocupación, pero distanciándose de un abordaje lingüístico-discursivo con el encuadre metodológico del Análisis Crítico del Discurso y de la Lingüística Crítica, la presente investigación realizó el tratamiento de los datos en el marco del análisis socioeducativo del discurso (Martín Criado 2014). Esta metodología es de relevancia para "dilucidar el juego de tensiones y ambivalencias en que se mueven prácticas y discursos (...) y ver las estrategias simbólicas para legitimar o deslegitimar a los distintos sujetos y sus prácticas -de ahí el énfasis en situar todo discurso en un espacio de discursos y todo enunciado en la estrategia general de presentación de sí" (Martín Criado 2014: 133). La línea de análisis que se sigue postula una interrelación entre las noticias y la práctica social que los produce, por eso referiremos a práctica discursiva. Desde esta perspectiva el uso de ciertos actos de nombramiento y clasificación en las notas estará determinado por las convenciones socialmente aceptadas para el discurso en el que se inserta. A su vez, los límites de ese discurso estarán relacionados con las condiciones de reproducción/transformación que posibilitan las estructuras sociales existentes. El desafío consistió en establecer dimensiones de descripción y análisis para elucidar el tratamiento de las configuraciones familiares en los discursos mediáticos sobre las violencias en las escuelas.

Respecto a la contextualización de los discursos, es relevante mencionar que las notas analizadas estuvieron atravesadas por una temporalidad educativa particular, en la cual se extendió la escolaridad obligatoria de los jóvenes argentinos. En 1993, en la Ley Federal de Educación se extiende la obligatoriedad a octavo y noveno año, y en 2006, en la Ley de Educación Nacional se establece la escuela secundaria obligatoria. Estos aspectos son relevantes en la lucha simbólica por la representación de la escuela y los estudiantes y sus familias. Como parte de los propósitos de la investigación, se encuentra la intención de contribuir a una alternativa teórica y práctica frente a aquellas visiones estigmatizantes que portan y operan desde una mirada de los estudiantes y determinadas configuraciones familiares como sujetos peligrosos de los cuales habría que resguardarse.

Es pertinente especificar cómo se realizó el estudio de las caricaturas presentes en las coberturas. En un primer momento se examinó el nivel morfológico y el nivel compositivo de las fotografías sin limitarse a una interpretación inmanente, sino que se analizó la concepción socioeducativa que se expresa a través de estos niveles, conformando un estudio global. Como sostiene Amalia Barbosa Martínez "el método documental no solamente supone la superación de un análisis formal e inmanente, sino también la superación de un análisis autónomo" (Barbosa Martínez 2006: 400).

En los siguientes apartados se desarrollará los dos núcleos relevantes de la temática: el tratamiento de las configuraciones familiares en los discursos mediáticos sobre las violencias en las escuelas y el tratamiento especifico de los episodios de violencia desde los familiares de los estudiantes hacia estudiantes y/o trabajadores del establecimiento educativo. 


\section{Las configuraciones familiares de los estudiantes en el discurso mediático}

Cuando habitualmente se habla del "problema de la violencia" se produce una reducción del campo, por deslizamiento semántico, que vuelve visibles aquellas formas de violencia que tienen que ver con lo individual y con lo familiar, y torna invisibles aquellas que tienen que ver con lo institucional y con lo instituido socialmente.

Un hallazgo obtenido a lo largo de la investigación consiste en advertir una referencia sistemática en las producciones discursivas a "la familia" como institución medular para la comprensión de los procesos de socialización y de subjetivación de los estudiantes. Por ejemplo, desde las coberturas se menciona a psicólogos especializados en adolescencia y familia (El Día, 24-11-11) como una voz autorizada para solucionar los problemas de violencia en el espacio escolar. Se observan muchos intelectuales "integrados" en los discursos mediáticos que favorecen al orden establecido y contribuyen a dar mayor eficacia simbólica. Bourdieu señala: "Y la fuerza del nuevo orden dominante es que ha encontrado los medios específicos de "integrar" (en ciertos casos podríamos decir "comprar", en otros "seducir") una fracción cada vez más grande de entre los intelectuales, y ocurre igual en todo el mundo." (1997a: 4).

Se identifica una apelación a las relaciones intergeneracionales en las situaciones de violencia en las escuelas (Saez, 2014). Tras el análisis del lugar de los adultos en las coberturas y la representación del espacio social de las familias en las instituciones educativas, se observa que prevalecen modos de abordaje simplistas e uniformes que visibilizan las violencias en las escuelas como producto de una invasión de la violencia social, con adultos incompetentes para intervenir. En segundo término, se identifican a ciertas configuraciones familiares socialmente desfavorecidas como individuos en riesgo, donde el accionar adulto se ve cuestionado.

Durante el período estudiado en las coberturas de la prensa platense sobre las violencias en el espacio escolar se asume a determinadas configuraciones familiares como un grupo en riesgo. Este enfoque considera a estos grupos humanos como problema o riesgo que se corrige y no como potencialidad que se promueve. A continuación, se presentan algunas menciones:

\footnotetext{
"Socialmente considerados como precoces delincuentes, los chicos son, en realidad, el emergente de un país creciente de políticas adecuadas para proteger a los hijos de familias en riesgo". (Hoy, 23-06-1994)

"Jóvenes que son tranquilos y solo quieren divertirse los fines de semana. Pero que ven una violencia que crece y que toma parte de sus pares. Apuntaron al exceso de alcohol, al consumo de drogas, y también a la familia y a la violencia de los adultos. A esa que protagoniza la generación de sus padres y que se da a pleno día porque quienes deberían contenerla son sus protagonistas". (EI Día, 22-08-1993)

"Se sabe que hay de por medio entornos familiares desfavorables, carencias de índole socioeconómica, falta de compromiso por parte de muchos padres, abuso de alcohol o consumo de drogas, ausencia de ejemplos por parte de los mayores: se trata de una espiral de factores negativos, que ponen finalmente en jaque la capacidad del sistema educativo, hoy volcado en buena medida a cubrir tareas asistenciales en lugar de las específicamente educativas". (El Día, 10-06-2011)
}

El enfoque de riesgo considera la precaria situación estructural en la que crecen y maduran las nuevas generaciones. Muestra la existencia de amplios sectores excluidos. Sin embargo, no hace referencia alguna a la condición ciudadana de los integrantes de estos 
grupos y a los derechos inalienables que les corresponden en tal sentido. Alternativamente, sin desconocer que enfrentan agudas $y$ evidentes situaciones de riesgo, se asume que los grupos familiares están compuestos por ciudadanos y tienen, desde dicha condición, derechos que la sociedad y el Estado deben respaldar, procurando que estos tengan la más extendida y profunda vigencia efectiva a todos los niveles. El cambio de paradigma es sumamente relevante, en la medida en que permite disputar sentidos sobre los modos de representar los grupos familiares. El discurso autorizado enfatiza también esta mirada de la familia. Veamos una mención:

\footnotetext{
"ENTREVISTA AL JUEZ DE MENORES JULIO BARDI. Es alarmante que a mayor riesgo social haya menor contención familiar. El magistrado platense afirma que los menores no adquieren valores esenciales ni contención inmediata en el núcleo familiar. Explica la 'Tragedia de Patagones' por la ausencia de prevención y represión en sentido legal: 'El colegio no puede inculcar lo que la casa y el Estado no les ofrecen."' (Hoy, 01-10-2004)
}

Ahora bien, en las coberturas analizadas se evidencian aspectos de la relación entre las configuraciones familiares y los procesos de escolarización. Desde la sociología figuracional, son vinculaciones complejas (Dantes 2015; Sarat 2014; Barbosa 2007). Tanto la familia como la escuela cumplen un rol de agencia civilizadora (Pooli 2009) que transmiten el entramado cultural de las sociedades. La educación familiar y escolar marca las trayectorias escolares y constituyen modos específicos de un comportamiento civilizado. Los individuos, por medio de sus relaciones, van estableciendo interdependencias inevitables. La forma de interacción entre padres, madres, profesores y directores revela las interdependencias mutuas existentes y las tenciones que emergen de tales relaciones. Las relaciones entre individuos, que componen la institución educativa y la familia, se quedan envueltas en relaciones cotidianas de cuidados y educación de los estudiantes y se configuran de forma contradictoria (Dantes 2015). Se identifican encuentros y desencuentros entre individuos interdependientes y que, por el hecho de estar unidos por una intensa relación, están constantemente produciendo relaciones de poder (Sarat, 2014). En continuación con estas observaciones Barbosa (2007) propone repensar las nuevas dimensiones de ser niños y jóvenes en este momento histórico. Así, resulta relevante repensar la socialización de los estudiantes desde el entrelazamiento de las culturas escolares, consideradas legítimas, y sus relaciones con algunas de las culturas familiares consideradas ilegítimas por la escuela. Conocer las culturas familiares permite ampliar la comprensión de los estudiantes y posibilita la construcción de un proyecto de escolarización que entrelaza las culturas escolares y las culturas de las familias en la sociedad contemporánea. La formulación de una "educación de calidad" sólo puede conseguirse mediante el establecimiento de propuestas que contengan estos discursos.

\section{Episodios de violencia desde los familiares de los estudiantes hacia estudiantes y/o trabajadores del establecimiento educativo}

En trabajos anteriores se ha evidenciado cómo familiares de los estudiantes participan de episodios de depredación de los edificios escolares (Saez 2017). En continuidad, en este artículo avanzaremos en el análisis de aquellas situaciones en las que los que familiares de los estudiantes amenazan o agreden a miembros del cuerpo docente. Dado que surgieron como episodios recurrentes y relevantes en el trabajo de campo. 
Los motivos de los hechos que se evidencian en el discurso mediático fueron dos: el maltrato previo de un integrante del cuerpo docente hacia un estudiante y/o la disconformidad con la calificación en una evaluación. Como se evidenció en otros trabajos (di Nápoli 2012) el rendimiento escolar y las calificaciones constituyen un núcleo de sentido que está vinculado a la adjetivación de "violento" en el espacio escolar.

\section{Veamos algunos ejemplos:}

"Fue capturada por tres encapuchados. La subieron a los empujones a un auto. Antes de liberarla, le dijeron: 'Este es un aviso, la próxima te matamos a vos o a uno de tus hijos'. La mujer sospecha de padres de alumnos reprobados". (Hoy, 10-07-2004)

“'En general los docentes tenemos problemas cuando desaprobamos, somos amenazadas', dijo la maestra de Matemáticas y Ciencias Naturales del primer y segundo ciclo de la Educación General Básica". (Hoy, 07-10-2004)

"Mamá agredió a la maestra de su hijo. La madre de un alumno de una escuela de la ciudad pampeana de General Pico golpeó y tomó de los pelos a una docente que cacheteó a su hijo. Al parecer, la docente intervino para separar a dos alumnos de sexto grado que se peleaban en el patio de la escuela, durante el recreo, pero en vez de tranquilizarse, uno de ellos comenzó a insultarla, por lo que la docente le dio una cachetada". (El Día, 07-05-2005)

"Un preceptor y el padre de una alumna terminaron a las piñas. El preceptor habría agredido verbalmente a una chica a raíz de un problema que data del año 2000. El padre de la joven lo increpó en la escuela. El celador fue separado del cargo". (Hoy, 07-05-2005)

La familia de los estudiantes aparece en estas notas como el lugar en el cual sentar las bases de las soluciones a la violencia en las escuelas. Los discursos destacan la capacidad de decisión y actuación de las familias como fuertes a partir de las cuales buscar respuestas posibles, dando por supuesta una autorresponsabilización de la familia de los alumnos tipificados como violentos. Algunos fragmentos de las notas que muestran esto son:

\begin{abstract}
"Una labor mancomunada entre familia y escuela en una dirección debe planificarse con detalle. Es menester tener en cuenta que una juventud no instruida, no educada adecuadamente carece de voluntad para realizar esfuerzos, carácter para vencer obstáculos y dificultades. Y con ese cuerpo enfermo no se podrán rever grandes problemas del país. Es menester dar a nuestra juventud el carácter, voluntad, temperamento, conocimientos que terminen con la inmoralidad y corrupción". (El Día, 17-04-1993)
\end{abstract}

"Sin duda, forma parte de un deterioro general que es necesario revertir rápidamente desde la educación en el seno de la familia, para que esta se fortalezca luego en los distintos niveles educativos. No entender la importancia de revalorizar la educación y el respeto es atentar contra nuestro propio futuro. $Y$ nos inhabilita para ejercer cualquier otra crítica o exigir otros derechos". (Hoy, 06-09-2005)

"Si no resulta posible individualizar a los estudiantes que realizaron los destrozos, los colegios deben trabajar desde el aspecto formativo, asumir las responsabilidades, hacer las disculpas que correspondan colegio por colegio, llamar a los papás y trabajar de aquí a fin de año". (Hoy, 07-09-2005)

"La idea de ambas instituciones es tal como se aconsejó desde la UNLP: trabajar con los estudiantes dentro y fuera del ámbito escolar. Para Oliva, la reflexión debe alcanzar a directivos, docentes y alumnos. En tanto que, fuera de la institución, la sociedad también debe hacerse cargo de su responsabilidad. Y los papás deben colaborar, ya que sin duda ellos son los primeros educadores". (El Día, 08-09-2005)

"La comunidad educativa apunta a los padres para frenar la violencia escolar". (Hoy, 01-10-2004)

“¿El problema está en casa?” (Hoy, 16-06-2005)

En muchas de las coberturas los aspectos relacionados con actitudes violentas quedan asociados al hecho de enfrentar problemas vinculares en sus casas. Como sostienen Dantes y Sarat: "el niño necesita crecer e insertarse socialmente, delante de eso, el ambiente familiar es de gran importancia, una vez que ejerce una fuerte influencia en los comportamientos y actitudes de los niños cuando se relacionan con personas fuera del ambiente de su hogar" 
(Dantes y Sarat 2016: 295). Pero es importante que eso no se torne una visión general, con el riesgo de desarrollar una visión prejuiciosa y estigmatizante

Se consideraría entonces que es posible identificar a los individuos en riesgo según sus antecedentes familiares o, como afirma Kaplan (2014), una suerte de genética social. Serán aquellos que posean una historia de vida familiar que los hace susceptibles de ciertas condiciones de futuro. Como ya lo sostiene Patrick Champagne (1999), se estigmatiza a los segmentos de la población más vulnerable. Lejos de ayudarlos, estos discursos suelen crear una imagen negativa. Contribuyen a su estigmatización (Goffman 2001), sin duda involuntaria y resultante del funcionamiento mismo del campo periodístico, que se extiende más allá de los acontecimientos que provocan. Estas prácticas discursivas pueden pensarse como un espacio simbólico donde se categoriza a ciertas personas y a los atributos que se consideran como corrientes y naturales, como puede ser la violencia, en las poblaciones más vulnerables. Veamos algunas evidencias:

"Según lo que dejaron trascender los voceros, la vivienda de Carmen de Patagones en la que residía la familia de Junior, por su precariedad, no tenía el lugar indicado, y el uniformado hizo lo que tenía a su alcance y la guardaba en un placard. Sin perjuicio de ello, se llegó a la conclusión de que correspondía la sanción". (Hoy, 02-08-2005)

"Méndez evaluó que estos casos se producen por el marco social 'que violenta derechos y posibilidades de los padres', cuyo principal problema es la carencia de trabajo. Según entiende la subsecretaria esta situación 'es transmitida a los chicos y después repercute en la escuela'”. (Hoy, 13-08-2005)

Las coberturas analizadas evidencian un modelo idealizado de familia con determinadas características en la economía del hogar, sin conflictos o problemas, como "adecuado" para la educación de los estudiantes. Por ende, los grupos familiares imaginados como "sin la suficiente sustentabilidad económica" tienen más dificultad de interacción y son una posible causa de las dificultades para convivir en el espacio escolar. Estas formas de abordaje mediático pueden construir una visión prejuiciosa y estigmatizante sobre determinados grupos familiares.

Desde el discurso mediático, la familia es percibida según sus condicionamientos materiales desiguales: víctima y a su vez culpable. En las prácticas discursivas, parecen deslizarse sentidos sobre un modelo de familia ideal. En estas formas de nominación se producen operaciones de significación que se caracterizan por agrupar una serie de fenómenos de origen muy diverso y que generalmente no pueden sostener su coherencia, en tanto categoría homogénea, cuando se los somete a un análisis más preciso.

En relación con las trayectorias escolares, un factor presente en la conformación de las desigualdades de acceso al conocimiento es la exposición a situaciones de vulnerabilidad del grupo familiar al que pertenecen los estudiantes. Al respecto, López (2008) señala:

\footnotetext{
Este bienestar puede verse amenazado por situaciones propias de la dinámica de los hogares, como por ejemplo la pérdida de trabajo del principal proveedor de ingresos -o el paso a un trabajo menos estable-, la separación del núcleo conyugal o el nacimiento de un hermanito, que retira temporalmente a su madre del mundo laboral al mismo tiempo que se incrementan los gastos familiares. En estas circunstancias, en que se ven resentidas las bases de acceso al bienestar de cada hogar, no todos tienen la misma capacidad de reponerse sin que se vea afectada la situación de sus niños y adolescentes (López 2008:70)
} 
Los sectores socialmente desfavorecidos se exponen a arbitrar diversas estrategias en pos del sostenimiento de la vida cotidiana. Aún con legislaciones vigentes en casi todos los países que prohíben el trabajo infantil, muchas organizaciones familiares deben sumar el esfuerzo del trabajo de sus hijos para completar sus ingresos. Por ende, entra en juego otra variable (trabajo infantil/ juvenil) que influye en lo que sucede en el espacio escolar.

Ahora bien, las miradas sobre la familia requieren situarla también en el marco de los debates acerca de las transformaciones de las sociedades contemporáneas y las consecuencias subjetivas que conllevan (UNICEF y UDELAR 2003). Para profundizar el análisis es necesario tomar los aportes de Victoria Orce (2012), quien alude a que la estructura de la familia se modifica en función de los cambios que experimenta la sociedad de la cual forma parte. Afirma que las nuevas configuraciones familiares se definen por contraposición a la familia "normal", tornándose necesaria la pregunta acerca del estatuto de la "familia real". Para la autora cada relación familiar es un proceso, y la imagen de la familia ideal, perfecta, armónica, resulta un cliché, aunque sea añorada con nostalgia. Así pues, en los discursos propuestos parecen no cuestionar esta imagen de familia. Observemos algunas citas:

\footnotetext{
"Matías y el compañero que lo hirió parecen ser buenos chicos. Inteligentes y sin problemas de conducta. Con familias que los adoran y los contienen. Víctimas de un impulso que pudo ser fatal. Por estas horas, los dos están mal, pero sus afectos están dispuestos a ayudarlos". (EI Día, 10-09-2000)

"La pasión por ese deporte y la relación que los amigos de Diego tenían con su madre y sus hermanas convirtieron el living de la modesta casa en lugar de encuentro para tomar mate y ver los partidos de fútbol por televisión". (Hoy, 25-05-2001)
}

\begin{abstract}
"La familia del chico acusado estaba en la mira de gran parte de los vecinos de Melchor Romero. Muchos los acusan de formar una banda que se dedicaba a asolar la zona. Su método: la amenaza". (Hoy, 25-05-2001)
\end{abstract}

Desde la sociología figuracional se puede asumir como supuesto la imagen de las familias como configuraciones de seres humanos en interdependencia. Como cualquier otra composición social es relativamente independiente de los individuos concretos que la constituyen aquí y ahora, pero no es independiente de todos los individuos. Se desprende de esta posición epistemológica una serie de supuestos teóricoempíricos generales para estudiar el vínculo entre violencia y las configuraciones familiares. Sobre la configuración familiar podemos afirmar que: es una categoría con historia; es constructora de subjetividad; involucra siempre una dimensión relacional; los umbrales de sensibilidad y las formas de comportamiento cambian a lo largo de la historia objetivada e incorporada; e involucra siempre una relación social atravesada por el poder. Por lo cual, los discursos mediáticos forman parte de una lucha simbólica por la representación de las familias y contribuyen a crear una sensibilidad sobre estos grupos sociales.

Las prácticas discursivas de los medios de comunicación no son acciones aisladas, sino que reciben y proporcionan productos socialmente clasificados, que se objetivan mediante un sistema de adjetivos. En las notas periodísticas se evidencia la puesta en práctica de taxonomías socialmente constituidas que son en general la interiorización de oposiciones de campo social. Bourdieu va a plantear que "las formas de clasificación son formas de dominación, que la sociología del conocimiento es inseparablemente una sociología del reconocimiento y del desconocimiento, es 
decir de la dominación simbólica" (Bourdieu 1988: 35). Se produce una caracterización de la familia violenta donde se expresan cualidades distintivas a las maneras de marcas de calidad social (Kaplan 2013). Explorar las formas de designarla supone la hipótesis de que los vocablos asociados configuran un sistema de significación. En las notas analizadas la familia violenta queda vinculada a: familia disfuncional, adicta, delincuente, en crisis, en descomposición, con padres separados, con presiones, no contiene, no transmite valores esenciales, descuidada, no registra la situación psicológica de sus hijos, no detecta problemas, con adultos ausentes, atemorizadores, con enfermedades psiquiátricas, creadores de monstruos, con vivienda precaria, con padres carentes de trabajo.

Estas formas de nombramiento hacen énfasis en las carencias mentales y morales de ciertos grupos familiares. Están acompañadas muchas veces de caricaturas, en una de ellas se representa una familia que asiste a un espacio terapéutico para "mejorar la contención familiar" (Ver Imagen 1 Caricatura sobre la configuración familiar). La imagen pone en la escena a los adultos de la familia observando hacia un fuera de campo. En el centro está el padre de la familia en un diván. Observemos:

En otro de los casos (Ver Imagen 2 Caricatura sobre la configuración familiar) se presentan actores familiares descuidados y que no transmiten valores esenciales. El espacio central de la imagen se representa un diálogo de un padre con su hijo. Veamos:

En las coberturas se recurre al ya mencionado enfoque de riesgo de los grupos familiares. Dados los estereotipos con que se mira a estos
Imagen 1: Caricatura sobre la configuración familiar

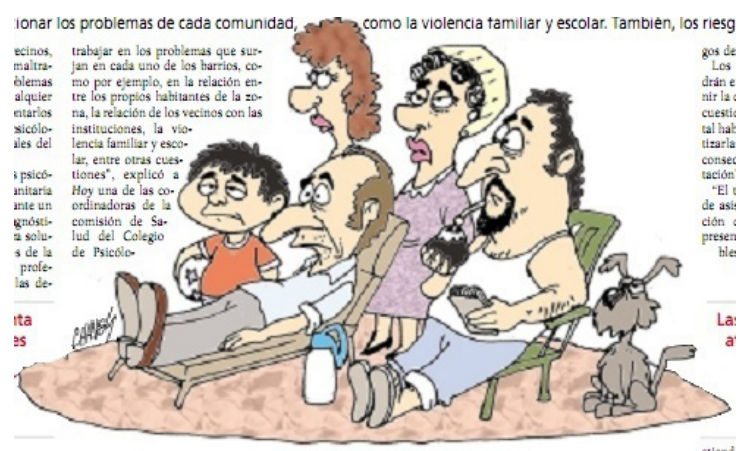

Fuente: diario Hoy, 18-10-2004

Imagen 2: Caricatura sobre la configuración familiar

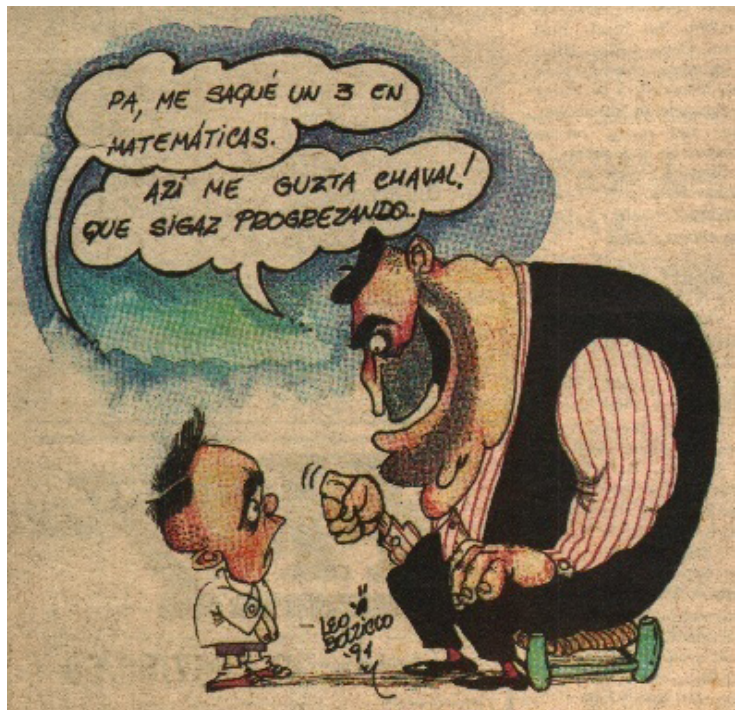

Fuente: diario Hoy, 16-06-1994 
grupos, se proponen el enfoque de vigilancia sobre su comportamiento y los castigos que un comportamiento inadecuado debe tener. Así, en esta forma de visibilizar las violencias en el espacio escolar se instalan prácticas discursivas criminalizantes y estigmatizantes sobre ciertos grupos, a la vez que seadjudica la responsabilidad de las situaciones de violencia exclusivamente al individuo o a su hogar o condición de origen. El mal comportamiento de un alumno de ningún modo sería comprendido desde la perspectiva de la desigualdad social, sino que termina siendo explicado por las carencias morales y de valores del sujeto o su familia.

Sin embargo, desde la sociología figuracional, se afirma que no hay configuraciones familiares intrínsecamente violentas. Como sostiene Kaplan (2016) "La violencia contra sí mismo y contra los otros es una disposición potencial que se activa en una trama vincular intersubjetiva en figuraciones en proceso" (p.105) Las violencias de los individuos y grupos están asociadas, aunque no mecánicamente, a las estructuras del comportamiento social y a las estructuras de personalidad de una época. Por ejemplo, los niños en relaciones familiares más cálidas e íntimas, han experimentado un tipo de disciplina o control social menos dirigido a la obediencia que al autocontrol y la autonomía, esto es, a aprender a pensar y decidir por sí mismos (Wouters 2016; Alwin 1988). Aquello que se considera como comportamiento violento en una cierta sociedad puede no serlo en otras; o inclusive en esa misma sociedad en otro momento de su historia.

\section{Conclusiones}

El presente estudio permitió un avance en la conceptualización de las violencias en los espacios escolares a través de los medios gráficos de comunicación. El análisis socioeducativo del discurso constituye una herramienta privilegiada para estudiar de qué manera los discursos sociales, en este caso el de la prensa, sostienen un ordenamiento y una determinada clasificación del mundo, de sus eventos y de sus participantes.

Desde éste se identificó como escenario los episodios de violencia desde los familiares de los estudiantes hacia estudiantes y/o trabajadores del establecimiento educativo.

Las luchas simbólicas por los actos de clasificación social y el posicionamiento dentro del espacio socialmente jerarquizado pueden observarse en la presentación de algunos grupos familiares como en riesgo. Sin hacer visibles sus derechos, se los considera como problemas que se corrigen.

Específicamente, proponen a las familias como pilares para asumir el desafío del reencauzamiento. Los grupos familiares son representados desde modelos ideales y son percibidos según sus condicionamientos materiales desiguales, responsables y a su vez víctimas de los episodios de violencia en las escuelas. Se hace una linealidad entre familia pobre/ familia en riesgo/ familia inmadura/ familia del mal ejemplo, que promueven los comportamientos violentos de los estudiantes. Estas evidencias son de relevancia, en tanto los medios masivos de comunicación tienen un rol fundamental en la configuración de los ejes sobre los que se articulan las figuras de lo amenazante y los sentimientos que ellas despiertan.

Así también, desde el discurso de la prensa es posible identificar a ciertas configuraciones 
familiares socialmente desfavorecidas como individuos en riesgo. Aquellos que poseen una combinación particular de biología e historia de vida familiar, que los hace susceptibles de unas ciertas condiciones de futuro. Encontramos una continuidad con lo que afirma Patrick Champagne (1999) que se estigmatiza a los segmentos de la población más vulnerable. Esto va creando nuevas sensibilidades sobre ciertos grupos familiares. En este carril, es necesario considerar la potencialidad que tienen las representaciones mediáticas, productoras de sentido social, para generar información, conocimiento y consentimiento respecto de las relaciones de igualdaddesigualdad. Un tipo de discurso que opera distinguiendo individuos y grupos y argumenta la cuestión de las desigualdades sociales sobre la base de cualidades individualizantes. Estas prácticas discursivas se revisten de eufemismos quedando enmascarados supuestos equivalentes a los del determinismo biológico y de los racismos cotidianos, al neutralizar la desigual distribución del poder que subyace y explica las diferencias, en el sentido de desigualdades, entre sujetos sociales.

La percepción habitual de los discursos mediáticos tiende a naturalizar las diferencias que surgen de la apropiación diferenciada de un capital cultural, atribuyéndoles a causas naturales o al medio familiar cosificado. Diversas formas de la violencia pueden verse sometidas a procesos de deslizamiento de sentidos que reducen fenómenos muy complejos en algo homogéneo y simple. Se da visibilidad a algunas formas de violencia, como por ejemplo las familiares y las individuales, al mismo tiempo que invisibiliza otras, como las institucionales y estructurales. Estas construcciones sobre las familias de los estudiantes están atravesadas por representaciones estigmatizantes (Goffman 2001: 45), como si fueran grupos amenazantes o sospechosos. En este sentido, el análisis de las representaciones mediáticas sobre la temática pretende ser insumo para la reflexión. Se trata de contribuir a cuestionar la mirada que construimos sobre los grupos familiares como así también, las prácticas que desarrollamos, para poder generar espacios en los cuales encontrar nuevas alternativas, que nos alejen de los reduccionismos y antagonismos.

Respecto a los trabajos anteriores sobre las representaciones de las configuraciones familiares en el discurso mediático (Sosenski y López León 2015; Saez 2013), se haya como novedoso que en los discursos sobre las violencias en las escuelas se representan familias de distinto origen socioeconómico. Con mayor visibilidad las que pertenecen a sectores socialmente desfavorecidos y de menor presencia las otras. Surge como hipótesis interpretativa que esta variación se debe a que el contenido de los discursos mediáticos es sobre episodios de violencia, un fenómeno considerado socialmente negativo porque reviste la idea de desviación (Villanueva 2005).

Por su parte, en continuidad con los estudios anteriores (Sosenski y López León 2015), este trabajo evidencia que los medios de comunicación reproducen la representación de que los vínculos en el núcleo familiar inciden en los comportamientos de los niños y jóvenes. A través de su discurso enfatizan que los menores tendrán relaciones más pacíficas en proporción al vínculo con su núcleo familiar. En este sentido es pertinente aclarar que hay investigaciones (Valdés Cuervo, Carlos Martínez, Tánori Quintana y Madrid López 2016) que muestran que las características del funcionamiento familiar afectan el desarrollo de emociones, tales como la empatía y la vergüenza, las cuales se 
asocian con una menor frecuencia de agresión entre estudiantes. Sin embargo, producir una visión general sobre esta relación corre el riesgo de promover una mirada estigmatizante.

Ahora bien, las coberturas periodísticas naturalizan la producción del cuidado a cargo de las configuraciones familiares. Lo que queda invisibilizado es la falta de producción del cuidado por parte de las políticas públicas. Históricamente, en el contexto argentino, el cuidado ha sido una cuestión relegada a la esfera privada (León y Florito 2016). La producción de cuidado está concentrada en la esfera privadayes un asunto del cual las familias deben encargarse, incluso en el marco de la denominada "crisis" en la materia que experimenta la región (Rico 2012). A pesar de la ampliación en cobertura e inversión de los sistemas de protección social latinoamericanos, el cuidado no ha sido incluido como uno de los riesgos que comprometen el bienestar de la población. Entre los factores que contribuyen a esta deuda pendiente hay algunos elementos estructurales y otros institucionales que deberán ser derribados para poder avanzar en la incorporación del cuidado como política de estado. Entre los factores estructurales se puede mencionar la naturalización del rol de la familia como proveedora de cuidados, y dentro de ella, la división sexual del trabajo que responsabiliza a la mujer como responsable casi exclusiva de las funciones reproductivas de la sociedad (Faur 2012). Estas concepciones permearon el diseño de los sistemas de protección social en el país, impidiendo que el cuidado sea abordado como un bien público que debe estar a cargo del Estado.

Esto sucede en una temporalidad educativa de ampliación de la obligatoriedad. Como ya se mencionó en apartados anteriores, desde 1993 hubo un cambio en la política de obligatoriedad educativa en la Argentina. Con la sanción de la Ley Federal de Educación, y luego con la Ley de Educación Nacional de 2006 se amplía los años de escolaridad obligatoria de los estudiantes. Estamos frente a la primera generación de muchos jóvenes que tienen la posibilidad de acceder a éste más años de enseñanza oficial. La ampliación de la cobertura de la escuela obligatoria pone de manifiesto la necesidad de construir herramientas específicas para procesos de expansión de los sistemas educativos. Con esto se hace referencia a lo presupuestario, los problemas relacionados con la enseñanza, las cuestiones vinculadas a la organización institucional y los puestos de trabajo docente, entre otras (UNICEF 2014). El ingreso de sectores de la población a las escuelas secundarias, que nunca antes habían accedido a ella y para los cuales no estuvieron destinadas desde su creación, pone en evidencia la necesidad de repensar sus formatos organizacionales y sus vínculos con las culturas familiares. La tradición de la escuela secundaria, eminentemente selectiva y destinada a la formación de las capas medias ya sea para permitir la prosecución de los estudios superiores o paralaformación para determinados tipos de trabajo (con la consecuente transmisión de valores asociados a ellas tales como la disciplina, el aprovechamiento del tiempo, el esfuerzo individual, entre otras cuestiones), choca con el ingreso masivo de otros grupos familiares con otras culturas, trayectorias de vida y expectativas.

En este contexto, la prensa representa ciertas configuraciones familiares asociadas a episodios de violencia en el espacio escolar y se los muestra como "grupos violentos". Sin embargo, estas situaciones de violencia, lejos 
de ser propias de un grupo, afectan a toda la institución. El cuidado es para todos los que forman parte de la vida cotidiana de la escuela, por eso las acciones y políticas de cuidado institucionales deben tener en cuenta a las personas adultas de la escuela (Guía Federal De Orientación Educativa 2014). Se considera al problema como dificultades para la convivencia escolar que exigen respuesta tanto del cuerpo docente como de las familias en su rol de adultos que acompañan a la educación de niños, niñas, adolescentes y jóvenes. Estas dificultades se producen tanto por lo que acontece dentro de las escuelas, como por todo aquello que ocurre fuera de ellas y de algún modo las implica y afecta. En este sentido, es necesario revisar las representaciones que circulan en los medios de comunicación para empezar a designar la situación en términos relacionales, donde se conceptualiza el mundo social identificando lo real no con sustancias sino con relaciones (Bourdieu 1988).

En síntesis, los resultados aportan evidencia empírica sobre la dificultad de la presentación de las configuraciones familiares en los medios de comunicación. Se hace pertinente aclarar que estos análisis tienen como limitación que se abordó el estudio desde de la prensa provincial y cabría preguntarse si las lógicas periodísticas se modificarían en la prensa nacional. Este aspecto será retomado en futuras investigaciones.

Por último, queremos hacer una observación general, creemos significativo resaltar la importancia de la participación de los grupos familiares en la escolaridad de los estudiantes. En este sentido, es necesario destacar la relevancia de esta investigación en tanto amplía la base empírica de las formas de presentación de las configuraciones familiares en el discurso mediático desde una perspectiva socioeducativa. Es importante que los medios de comunicación participen en el desarrollo de nuevas sensibilidades y disposiciones hacia los grupos familiares como sujetos de derecho, contribuyendo a renovar el compromiso social con una sociedad más democrática y más justa. Es imprescindible la participación activa de todos los sectores que integran a la comunidad educativa para lograr trayectorias escolares continuas.

\section{Bibliografía}

Alwin, D.F. 1988. "From obedience to autonomy: changes in traits desired in children". Public Opinion Quarterly 52: 33-52.

Barbosa Martínez, A. 2006. "Sobre el método de la interpretación documental y el uso de las imágenes en la sociología: Karl Mannheim, Aby Warburg y Pierre Bourdieu". Sociedade e Estado 21: 391-414.

Barbosa, M. C. S. 2007. "Culturas escolares, culturas de infância e culturas familiares: as socializações e a escolarização no entretecer destas culturas". Educação \& Sociedade 100: 1059-1083.

Bonilla Vélez, J. I. y Tamayo Gómez, C. A. 2007. Las violencias en los medios, los medios en las violencias. Bogotá: CINEP, Fundación Centro de Investigación y Educación Popular.

Bourdieu, P. 2002. "Cuestión de Palabras. Una visión más modesta del rol de los periodistas". Intervención en coloquio de Periodistas sin fronteras, publicada en (1992). Les mensonges du Golfe [Las mentiras del Golfo]. París: Arlèa. Esta conferencia se encuentra traducida en la recopilación Bourdieu, P. (2005). Pensamiento y acción. Buenos Aires: Libros del Zorzal. 1997. Entrevista a Pierre Bourdieu, realizada por P. R. Pires y publicada en O Globo (Río de Janeiro) el 4 de octubre de 1997. Traducción: F. Sanabria y G. Vargas.

1988. "Espacio social y poder simbólico". Cosas dichas. Buenos Aires: Gedisa.

Bourdieu, P. y Wacquant, L. 2005. "El propósito de la sociología reflexiva". Una invitación a la sociología reflexiva. Buenos Aires: Siglo XXI. 
Champagne, P. 1999. "La visión mediática". La miseria del mundo. Bourdieu, P (comps). Buenos Aires: Fondo de Cultura Económica.

Crespo Sánchez, F. J. 2015. "Un modelo de familia católica en la prensa mejicana del siglo XIX. Ejemplos a partir de del Seminario Católico". Revista electrónica editada por la Asociación Española de Americanistas: 14: 1- 21.

2014 "La imagen de la familia en la prensa religiosa de Murcia en los inicios del siglo XX". Hispania sacra, 134: 733-765.

Dantes C. 2015. Familia y educación infantil: relaciones interdependientes. Tesis presentada con el fin de cumplimentar con los requisitos finales para la obtención del título de Maestría en Educación, Facultad de Educación, Universidad Federal de Grande Dourados, Brasil.

Dantes, C. y Sarat, M. 2016. "Familia e institución educativa. Relaciones de interdependencia y poder". Educación y procesos de civilización. Miradas desde la obra de Norbert Elias. Kaplan, C.V. y Sarat, M. (comp). Buenos Aires: Editorial de la Facultad de Filosofía y Letras. 285-304

di Napoli, P. 2012. "Jóvenes, violencia y escuela: un análisis de las relaciones entre grupos de pares en dos escuelas secundarias de la Argentina". Revista Austral de Ciencias Sociales 23: 25-45.

Fairclough, N. 2008. "El análisis del discurso y la mercantilización del discurso público: las universidades". Discourse \& Society 2: 170-185.

Faur, E. 2012. "El cuidado infantil desde las perspectivas de las mujeres madres. Un estudio en dos barrios populares del Área Metropolitana de Buenos Aires". Las lógicas del cuidado infantil. Entre las familias, el Estado y el mercado. Esquivel, V., Faur, E. y Jelin, E. Buenos Aires: IDES-UNFPA y UNICEF.

Finocchio, S. 2009. La escuela en la historia argentina. Buenos Aires: Edhasa.

Goffman, E. 2001. Estigma la identidad deteriorada. Buenos Aires: Amorrortu.

Hipp T, R. 2006. "Orígenes del matrimonio y de la familia modernos." Revista Austral de Ciencias Sociales 11: 59-78.

Kaplan, C. V. 2016. "El racismo de la violencia. Aportes desde la sociología figuracional." Educación y procesos de civilización. Miradas desde la obra de Norbert Elias. Kaplan, C.V. y Sarat, M. (comp). Buenos Aires: Editorial de la Facultad de Filosofía y Letras. $99-118$

2014. "O capital emocional. Traçando linhas promissoras para a pesquisa em educação". Educação, Subjetividade e Diversidade: pesquisas no Brasil e na Argentina. Kaplan, C. V. y Sarat, M. (Orgs.). Ed. Universidade Estadual de Londrina: Brasil.

(dir.) 2013. Culturas estudiantiles. Sociología de los vínculos en la escuela. Buenos Aires: Miño y Dávila.

(dir.) 2009. Violencia escolar bajo sospecha. Buenos Aires: Miño y Dávila.

Lahire ,B. 1999. L'invention de l'illettrisme : rhétorique publique, éthique et stigmates. La Découverte: París.

León G. y Florito J. 2016. "Todo queda en familia. Juventudes y sistemas de protección social: El cuidado como riesgo." Cuadernos de Ciesal. Revista de estudios multidisciplinarios sobre la cuestión social.15: 110 - 133.

López, N. 2008. La escuela y los adolescentes. Tendencias Sociales y Educativas en América Latina. SITEAL.OEI. IPPE. UNESCO.

Martín Criado, E. 2014. "Mentiras, inconsistencias y ambivalencias. Teoría de la acción y análisis de discurso". Revista Internacional de Sociología 72: 115-138.

Martini, S. 2004. Periodismo, noticia y noticiabilidad. Buenos Aires: Norma.

Ministerio de Educación de la Nación Argentina. 2014. Guía Federal de Orientación Educativa.

Orce, V. 2012. "Socialización familiar, vínculos intrageneracionales y producción de violencia en la escuela secundaria". Con ojos de joven. Relaciones entre desigualdad, violencia y condición juvenil. Kaplan, C.V; Krotsch, L. y Orce, $\mathrm{V}$ (comps). Buenos Aires: Editorial de la Facultad de Filosofía y Letras, UBA. 113-141.

Piñuel Raigada, J. L.; Gaitán Moya, J. A. y García, F. 2007. "La violencia en la escuela a través de la prensa online de los periódicos de referencia en España (2003)". Revista Interuniversitaria de Formación del Profesorado 59-60: 75-98.

Pooli, J. P. 2009. "Socialización, educación y procesos civilizadores". Poder, prácticas sociales y proceso civilizador: Los usos de Norbert Elias. Kaplan, C.V. y Orce, V. Buenos Aires, Noveduc. 157-164

Raiter, A, y Zullo, J. (comp.) 2008. La caja de Pandora. La representación del mundo de los medios. Buenos Aires: La Crujía y Facultad de Filosofía y Letras, UBA.

Rico, M. N. 2012. Crisis del cuidado y políticas públicas: el momento es ahora. Santiago de Chile: CEPAL.

Saez V. 2017 "Discursos mediáticos sobre las violencias hacia los edificios escolares". Revista Actualidades Investigativas en Educación de Universidad de Costa Rica 17: 1-32.

2015. "Una mirada a la investigación sobre medios, violencia y escuela". Revista Entramado 11: 136-155 2014. "Producciones de sentido en el discurso mediático. Las relaciones intergeneracionales en las situaciones de violencia en las escuelas". Revista de Investigación del Departamento de Humanidades y Ciencias Sociales de la Universidad Nacional de La Matanza 6: 3-18.

Sarat, M. 2014. "Educação da Infância: pesquisas no Brasil e na Argentina". Educação, Subjetividade e Diversidade: pesquisas no Brasil e na Argentina. Kaplan, C. V. y Sarat, M. (Orgs.). Ed. Universidade Estadual de Londrina: Brasil.

Sosenski, S. y López León, R. 2015. "La construcción visual de la felicidad y la convivencia familiar en México: los anuncios publicitarios en la prensa gráfica (1930-1970)". Secuencia 92: 193-225.

UNESCO 2014. Cinco grandes conferencias regionales previas al Foro Mundial de la Educación de mayo de 2015 (en línea). Disponible en: http://www.unesco.org/new/es/education/ 
themes/ leading-the-international-agenda/education-for-all/ world-education-forum-2015/ regional-conferences/\#topPage

UNICEF y CEPAL. 2006. Efectos de la crisis en Argentina. Disponible en: <www.unicef.org/argentina/spanish/Efectos_ Crisis_en_Argentina_-_Documento_de_Difusion.pdf>.

UNICEF y UDELAR. 2003. NUEVAS FORMAS DE FAMILIA PERSPECTIVAS NACIONALES E INTERNACIONALES

Valdés Cuervo, A. A., Carlos Martínez, E. A., Tánori Quintana, J. y Madrid López, E. J. 2016. "Relación entre funcionamiento familiar, emociones morales y violencia entre estudiantes de primaria". Revista Mexicana de Investigación Educativa 71: 1093-1110.

Van Dijk, T. 2007. "Discurso racista". Medios de comunicación y sociedad. Igartua, J.J. y Muñiz, C. (eds.), Salamanca: Ediciones Universidad de Salamanca.

Verón, E. 1987. "Prefacio a la segunda edición". Construir el acontecimiento. Buenos Aires: Gedisa.

Didier Erudition. 1981. La presse. Produit, production, reception. París:

Villanueva, A. 2005. Violencia y escuela: lo dicho, lo hecho y lo que se muestra. El debate académico y la construcción de la violencia escolar en los medios. Tesina de grado con el fin de cumplimentar con los requisitos finales para la obtención del título de Licenciado en Ciencias de la Comunicación, Facultad de Ciencias Sociales, Universidad de Buenos Aires, Argentina.

Wouters, Cars 2016. “¿Hacia una integración del deseo y el amor? Erotización y sexualización desde 1880." Educación y procesos de civilización. Miradas desde la obra de Norbert Elias. Kaplan, C.V. y Sarat, M. (comp). Buenos Aires: Editorial de la Facultad de Filosofía y Letras. 15-50

\section{Fuentes consultadas:}

El Día enero 1993-diciembre 2011. Disponible en: www.eldia. com.ar. (Consultado el: 23 de mayo de 2012).

Hoy, enero 1993-diciembre 2011. Disponible en: www. diariohoy.net. (Consultado el: 15 de agosto de 2012).

Diagonales enero 2008-diciembre 2011. Disponible en: www. diagonales.com. (Consultado el: 10 de marzo de 2012).

Extra, enero 2002-diciembre 2011. Disponible en: www. diarioextra.com.ar. (Consultado el: 16 de octubre de 2012). 
